\title{
La València quatrecentista a través dels ulls d'un notari: les notícies de Jaume Vinader
}

\section{The 15th century's València through the eyes of a notary: the Jaume Vinader's news}

\author{
Javier Fajardo Paños \\ javier.jafapa@gmail.com \\ Miquel Faus Faus \\ maulet.cat@gmail.com
}

I. $S$.

\begin{abstract}
Resum: El present treball presenta un estudi previ i una edició completa de totes les notícies anotades pel notari valencià Jaume Vinader, conservades en els seus llibres notarials al llarg de gran part del segle XV (1419-1467). Aquestes petites cròniques ens permeten submergir-nos en alguns dels esdeveniments més importants de la centúria a través de la mirada i el record d'un notari, és a dir, a través d'una perspectiva diferent a les tradicionalment estudiades a partir de documentació emanada pels poders polítics del moment. En definitiva, el cas que ací es presenta obri una nova perspectiva d'estudi de les fonts notarials, generalment emprades per a estudis econòmics i socials.
\end{abstract}

Paraules clau: Vinader, notícies, notari, memòries

\begin{abstract}
This paper presents a study and a complete edition of all the news written by valencian notary Jaume Vinader, preserved into his notarial books during the major part of $15^{\text {th }}$ century (1419-1467). These little chronicles allow us to penetrate in some of the most important incidents of the century through the eyes and the memories of a notary, that is, through a different perspective from traditional ways based on sources emanated from the contemporary powe « « $\mathrm{r}$. In short, the case we introduce open a new perspective for notarial sources' study, normally used for economic and social studies.
\end{abstract}

Keywords: Vinader, news, notary, memory. 
Javier Fajardo Paños \& Miquel Faus Faus. La València quatrecentista a través dels ulls d'un notari: les notícies de Jaume Vinader

\section{Introducció}

En els territoris de l'antiga Corona d'Aragó comptem amb una riquíssima conservació de fonts documentals, sobretot amb el protagonisme especial dels registres notarials (Cruselles 1998). Aquesta font ha estat $i$ ho continua sent d'una extraordinària riquesa per als estudis d'història econòmica i social. Arxius com el del Reial Col legi Seminari de Corpus Christi de València o l'Arxiu del Regne de València ofereixen a l'investigador un immens ventall de possibilitats gràcies a l'important fons notarial que s'hi ha conservat. Tanmateix, protocols i notals ens poden il luminar més enllà dels inventaris, testaments, compravendes, activitats creditícies, almonedes o encants. Els autors dels registres comptaven amb el control d'una eina intel lectual que els atorgava un poder especial dins de la societat baixmedieval: l'escriptura. Aquests professionals de la ploma eren els dipositaris de la fe pública, és a dir, donaven un valor inqüestionable a les activitats privades.

No obstant això, molts d'ells demostren als seus quaderns un afany interessant que va més enllà de plasmar els quefers diaris de la societat valenciana i que demostra una voluntat de deixar una memòria cronística dels esdeveniments públics i privats dels quals n’eren testimonis. Així doncs, molts notaris escriviren al principi, al final o intercalats entre els seus documents, «notícies» de successos d'una gran varietat tipològica que van des de successos públics, com entrades reials a València o nomenaments de càrrecs, fins a records privats de l'entorn familiar (Pons 2010-2011). Altrament, molts d'aquests estaven presents a les principals escrivanies del país, com la de la Casa de la Ciutat de València, seu del govern local, o la Casa de la Diputació del General del regne de València. Aquestes escrivanies els permetien entrar en contacte amb el poder, com el cas de Gaspar Eiximeno, qui seria l'escrivà de la Sala de València a finals del segle XV i principis del XVI (Rubio 1995). Aquells com Eiximeno, que anotaven notícies de tipus polític als seus registres notarials, es converteixen amb els seus escrits en relators del món que els envolta, en coneixedors dels afers polítics locals, estatals i, en ocasions, fins i tot, internacionals

L'existència d'aquestes notícies ja va ser assenyalada per primer cop al País Valencià en l'any 1919 per part de Francisco Almarche Vázquez en la seua obra Historiografia valenciana: catálogo bibliográfico de dietarios, libros de memorias, diarios, relaciones...inéditas y referentes al antiguo Reino de Valencia (Almarche 1919). Seria sobretot el recull realitzat per Rodrigo Pertegàs, metge i historiador valencià, amb els seus treballs pòstums «Efemérides notariales», la primera publicació de notícies procedents de diversos notaris valencians (Pertegás 1930 i 1931). Més recentment els estudis de Vicent Escartí han contribuït a conèixer una mica millor la naturalesa d'aquestes notícies en el marc de la literatura memorialística privada. D’una banda, en el llibre Memòria privada: literatura memorialistica valenciana del segle XV al XVIII (1998), en el qual recorda l'existència d'aquestes petites manifestacions literàries, i d'altra banda, l'article sobre el notari Gaspar Eiximeno, en el qual realitza un estudi introductori i una edició d'algunes de les seues notícies conservades (Escartí 1995). Fonts similars, però, han estat estudiades en la resta de territoris de la Corona d'Aragó. En el cas mallorquí, Antoni Mas ha donat a conèixer una narració inèdita de la Germania mallorquina feta per Joan Morro, testimoni 
Javier Fajardo Paños \& Miquel Faus Faus. La València quatrecentista a través dels ulls d'un notari: les notícies de Jaume Vinader

directe dels fets que descriu (Mas 2013) i Ramon Roselló el relat per part del mateix notari del setge de Ciutadella en 1558 (Roselló 1990). En l'àmbit aragonés, Manuel Gómez de Valenzuela, recull tot un seguit d'anotacions vàries en documents notarials d'època foral en el seu llibre $A l$ margen de los protocolos notariales aragoneses, memorias y crónicas, antologia de poesia notarial y notes varias (1429-1711) (Gómez de Valenzuela 2015). Cal puntualitzar, però, que ens trobem davant d'uns textos amb una vàlua historiogràfica modesta, lluny de les grans cròniques medievals, ja que eren escrites per al seu ús privat. Més aviat, s’inscriuen dins de la tradició dels annals o dels dietaris personals.

Paral lelament, les lletres catalanes medievals compten amb una sèrie d'exemples que podrien ser classificats dins de la literatura memorialística o dels dietaris. Del segle XV valencià caldria destacar el dietari de Melcior Miralles, capellà d'Alfons el Magnànim, que recull alguns dels principals successos de la València del Segle d'Or. ${ }^{1}$ Al principat trobem un altre exemple paradigmàtic en el dietari o llibre de jornades de Jaume Safont, en aquest cas un notari català membre de l'escrivania de la Diputació del General de Catalunya que narra els principals esdeveniments del Quatrecents, amb especial atenció als avatars de la guerra civil catalana (1462-1472). ${ }^{2}$ Un dels trets més destacables d'aquestes dues obres, contemporànies als textos que analitzem, és la semblança en la seua forma compositiva i formal amb les notícies procedents dels notaris valencians. És a dir, parlem de notícies generalment breus escrites a partir de l'experiència personal directa o indirecta.

\section{Les notícies de Jaume Vinader}

Indubtablement, un dels autors més prolífics d'aquesta tipologia literària és el notari Jaume Vinader, com ja van assenyalar en el seu moment Almarche, Pertegás i Escartí. L'aportació d'aquests ha estat fonamental i valuosa en la nostra recerca, atès que contribuïren a donar a conèixer el notari que ens ocupa a través de l'edició d'algunes de les notícies més representatives. En aquest treball, però, volem contribuir i complementar aquests estudis previs amb l'edició i l'estudi complet de totes les notícies de Jaume Vinader. Parlem d'un notari del qual tenim documentada la seua activitat professional des de 1416 fins a $1470 .{ }^{3}$ Va viure i va exercir de manera continuada en la parròquia de Sant Martí de la ciutat de València, de la qual arribaria a ser conseller en els anys 1446, 1452 i 1457. Segons la documentació conservada, al llarg de la seua vida es va casar dues vegades, primerament amb Blanquina -qui va morir el 28 de juliol de 1439- , amb la qual va tenir quatre filles: Margalida, Ursoleta -totes dues moririen en el mateix any que la mare-, Beatriu i Isabel. ${ }^{4}$ I en segon lloc amb

1 En relació al dietari vegeu l'edició a cura de Mateu Rodrigo (2011).

2 En relació al dietari vegeu l'edició a cura de Josep Maria Sans i Travé (1992).

3 Es pot consultar el catàleg de l'arxiu del Patriarca en Andrés Robles, F. \& al. (1990).

4 APPV, Protocol de Bertomeu Queralt, 13 de juliol de 1439. Gràcies a una de les notícies anotades pel mateix Jaume Vinader, sabem que Isabel es va casar el 28 de novembre de 1438 amb Jaume Villalonga en la parròquia de Sant Martí.

SCRIPTA, Revista internacional de literatura i cultura medieval i moderna, núm. 13 / juny 2019 / pp. 1 - 21 ISSN: 2340-4841 · doi:10.7203/SCRIPTA.13.13376 
Javier Fajardo Paños \& Miquel Faus Faus. La València quatrecentista a través dels ulls d'un notari: les notícies de Jaume Vinader

Isabel, filla de Bonanat, d'ofici argenter. ${ }^{5}$ Segons es pot veure en el seus protocols, va mantenir una clientela centrada principalment en mercaders i menestrals, tot i que també visitarien la seua taula camperols de Russafa i de l'horta sud. D'entre les seues propietats conegudes, cal assenyalar un conjunt de terres en Silla.

En les pàgines dels seus llibres notarials hem pogut trobar una trentena de notícies escrites en català (20) i en llatí (11), de les quals n’hem exclòs les referides a eleccions de jurats i justícies de València, per ser més freqüents - es tracta d'una pràctica força estesa entre els notaris de la ciutat-i perquè la informació que donen és de menor transcendència o interés. Predominantment, destaquen les referències a grans esdeveniments polítics succeits a la ciutat de València, tot i que també conservem una de caire familiar i altra referida a la preparació de pólvora en forma de recepta. Així, aquestes notícies ens permeten conèixer de primera mà alguns dels esdeveniments més rellevants de la València del XV a través dels ulls d'un testimoni contemporani. Formalment parlant, es tracta de notícies generalment breus acompanyades, en alguns casos, de dibuixos en la línia dels conservats en el Llibre de Jornades de Jaume Safont, com per exemple, un punyal, flames de floc per a referir-se a un incendi, l'escut reial amb les barres o una mitra per a la mort del bisbe de València. En funció de la seua temàtica, així doncs, hem classificat les notícies en quatre grans subgrups: les referides al món de l'Església, l’incendi de Genís Ferrer, les morts de la reialesa i les notícies internacionals, a banda d'un altre subgrup d'aquelles notícies no classificables en cap dels subgrups anteriors.

\subsection{El món de l’Església}

Del conjunt de notícies anotades per Jaume Vinader als seus llibres notarials destaquen les de temàtica religiosa $\mathrm{o}$, en el seu defecte, relacionades amb el món de l'Església i, més concretament, amb la Seu de València. Així, doncs, n'hem pogut identificar fins a dotze, d'entre les quals cal destacar la notícia sobre l'elecció d'Alfons de Borja, bisbe de València, com a papa de Roma, sota el nom de Calitx III. Altrament, un dels trets a destacar d'aquesta tipologia és la llengua emprada, ja que gran part d'aquestes són redactades en llatí, la llengua per excel lència de l'univers cristià, tot i que també s'empra el català, com en el cas de la ja mencionada elecció papal.

A través d'aquesta tipologia de notícies, per tant, podem conèixer alguns dels esdeveniments més importants que es donaren a la catedral valentina, $i$ que a ulls del nostre notari, mereixien ser anotades i recordades. Generalment, es tracten de fets de transcendència pública que permetien al conjunt de la població assabentar-se'n. En aquest sentit, la constant construcció de la Seu té la seua presència entre les anotacions de Vinader, com, per exemple, l'ascens del rellotge, dit Sant Miquel, al campanar nou, o l'inici de les obres dels nous fonaments del temple per a la construcció d'una

5 APPV, Protocol de Tomàs Argent, 20 de setembre de 1441. 
Javier Fajardo Paños \& Miquel Faus Faus. La València quatrecentista a través dels ulls d'un notari: les notícies de Jaume Vinader

nova arcada. Indubtablement, referències d'aquest tipus poden ajudar en recerques relacionades amb la història de l'art i, especialment, en estudis sobre la construcció de la catedral de València.

Així mateix, les morts i eleccions de papes representen un altre tema amb especial pes entre les notícies analitzades. Contemporani a un dels papes Borja, Vinader no deixa passar per alt les seua elecció com a successors de Sant Pere. L'elecció d'Alfons de Borja com a papa, fins aleshores cardenal i bisbe de València, hauria generat en la ciutat una gran excitació, segons el relat de Vinader, amb tocs de campanes en el Micalet de la Seu, processons i fogueres per tota la ciutat durant tres dies. Tanmateix, és interessant apreciar les diferències que trobem entre el relat de Vinader i el de Melcior Miralles, ja que aquest últim, al seu dietari, assenyala que les celebracions s'haurien allargat durant més de 10 dies (Rodrigo 2011: 231-232). Segurament, el cas de Miralles siga una hipèrbole amb l'objectiu d'exaltar la figura del nou papa Borja. Pot ser, sembla més verídica la xifra aportada per Vinader, ja que, segons l'escassa informació que tenim sobre ell, tot apunta a que no es tractaria d'un notari especialment proper als cercles del poder polític de la ciutat de València, i per tant, la seua visió dels fets narrats no estaria -hem de suposar- tan condicionada políticament com en el cas de Melcior Miralles. A més a més, cal recordar l'objectiu i la finalitat estrictament privada de les anotacions de Vinader, per a el seu ús particular, a diferència del Dietari, un obra estretament lligada als interessos del poder. Altrament, també deixa constància de la mort de l'antecessor del primer papa Borja, Nicolau V (1447-1455) i de l'elecció del seu successor, Pius II (1458-1464). Les morts de bisbes, altrament, també són recordades, concretament la del bisbe de València Hug de Llupià i Bagès, qui també ho seria del bisbat de Tortosa.

Com és lògic, les celebracions religioses, que tingueren lloc en la ciutat de València, també apareixen entre els records de Vinader. De la festa de Sant Lluís, per exemple, celebrada el 19 d'agost de 1430, se'ns recorda com una de les seues relíquies estava a la Seu, o la festa de Pasqua de l'any 1455, celebrada el 6 d'abril, dos dies abans de l'elecció del primer papa Borja. Cal destacar, a més a més, la descripció que trobem sobre la decoració que hi hauria a l'altar major de la Seu en els sermons que es realitzaven durant els dies de les festivitats majors, la qual consistia en ornamentar amb «panys de ras» una sèrie de barres que separaven al predicador de la resta d'assistents. Com a celebració, Vinader també decideix anotar la festa de l'Aparició del Senyor del 6 de gener de l'any 1458, en la qual es va celebrar en la nova església de la Trinitat de València «missa alta in altari maiorì. ${ }^{6}$

En darrer terme, dins d'aquesta tipologia cal assenyalar la indulgència lliurada pel papa Calixt III a la Seu de València en abril de 1458. Vinader apunta com va ser Antoni Bou, canonge de la Seu, l'elegit per a encapçalar l'ambaixada que aniria davant el papa. Seria aquest, doncs, qui en la seua tornada comunicaria la bona nova. Una rebuda que Vinader relata amb detall, amb la presència de tots

6 Es tracta del monestir de monges clarisses de la Santíssima Trinitat de València, fundat extramurs per la reina Maria en 1445, del qual en dit any era abadessa sor Isabel de Villena. La notícia ens parla del primer acte del cor nou del monestir en construcció, en la festa de la Epifania. Quasi amb certesa estaria present en l'acte la reina Maria, qui residia en el monestir. Sobre aquest fet i altres notícies de la fàbrica del monestir vegeu Benito Goerlich (1980).

SCRIPTA, Revista internacional de literatura i cultura medieval i moderna, núm. 13 / juny 2019 / pp. 1 - 21 ISSN: 2340-4841 · doi:10.7203/SCRIPTA.13.13376 
Javier Fajardo Paños \& Miquel Faus Faus. La València quatrecentista a través dels ulls d'un notari: les notícies de Jaume Vinader

els canonges, el Governador, els jurats de la ciutat i tota una representació de grans personalitats. L'ambaixada amb la indulgència papal, però, s'adreçaria abans d'entrar a València al Palau Reial, on estava la reina Maria, i posteriorment al Palau Episcopal. Gràcies, a Melcior Miralles i el seu dietari, podem constatar com la informació anotada pel notari és coincident amb la del cronista. Així mateix, Jaume Vinader també anota com en la festivitat de l'Assumpció de la Verge d'agost d'aquell mateix any va començar a fer-se efectiva la dita indulgència. ${ }^{7}$

\subsection{Genís Ferrer i l'incendi del Mercat de València}

El 26 de febrer de 1447, es produïa a Paiporta, en una alqueria propera a la ciutat de València, el que Melcior Miralles va anomenar «lo cas de Payporta cruel». Genís Ferrer, que havia segut jurat l'any anterior, juntament amb uns tals Piera, Gaçó (mosso d'aquest últim), un esclau d'en Genís i altres sis homes havien entrat armats a una casa de la present alqueria $i$ havien matat allí a la viuda de Joan Alfonso i a tres dels seus fills. Finalment, tiraren els cossos al pou de la casa i fugiren, deixant solament una supervivent, la filla menor de la família que s'amagà baix d'un llit. El fet causà un gran enrenou en la societat valenciana del moment, no sols per la gravetat del succés, sinó també pels implicats en l'acte.

Aquest fet traumàtic apareix enormement detallat en el protocol de Jaume Vinader de l'any 1447. Fins i tot, ens explica quin fou el desenllaç d'alguns dels perpetradors del crim, ajusticiats el 15 de març després que la ciutat mobilitzés els representants del justícia criminal i en capturés a quatre en la vila de Sant Mateu. Genís Ferrer, que havia planejat l'acte, fugí de València i per tant fou capturada la seua muller i castigada aquesta en el seu lloc. La raó pot estar relacionada a que diversos contemporanis assenyalaven a l'esposa d'aquest com la culpable última del dit crim. Així, Cristòfol de Montblanc en una carta enviada a Pere Tallada, canonge de Tarrassona, afirmava que aquella hauria incitat a atacar la família per tal que els feren «tant mal com poguéssen». Més tard, Jaume Roig en l'Espill apuntava directament a l'esposa de Genís Ferrer com la persona que havia maquinat el crim i la feia la principal responsable.

La història tampoc acaba ací ja que a l'endemà de l'ajusticiament ocorria el gran foc del mercat de València. De nou, la descripció de Vinader és una de les més completes amb les que comptem, gràcies a la qual podem veure quina àrea fou cremada. A més ens aporta un relat de com els representants religiosos de les parròquies s'acostaren al mercat per pregar per l'extinció o de com es pogué contenir l'incendi un cop canvià la direcció del vent. Allò que no menciona directament el notari és la relació que molts contemporanis feren, és a dir, vincular l'ajusticiament dels assassins amb l'inici del foc. Tant Cristòfol de Montblanc com posteriorment Jaume Roig assumien que

\footnotetext{
7 Gràcies al dietari de Melcior Miralles, on podem consultar una descripció detallada de la indulgència en qüestió, sabem que el preu que havien de pagar el fidels per a aconseguir el perdó dels seus pecats era de deu sous en moneda.
}

SCRIPTA, Revista internacional de literatura i cultura medieval i moderna, núm. 13 / juny 2019 / pp. 1 - 21 ISSN: 2340-4841 · doi:10.7203/SCRIPTA.13.13376 
Javier Fajardo Paños \& Miquel Faus Faus. La València quatrecentista a través dels ulls d'un notari: les notícies de Jaume Vinader

el responsable del incendi havia estat Genís Ferrer que des del seu exili hauria ordenat aquesta venjança. Els rumors i les acusacions que el declaraven com a culpable l'impediran tornar al regne de València fins a 1463 quan el rei Joan II li atorgà un guiatge especial que permetia la seua entrada.

El gran foc destruí desenes de cases i tallers a la plaça del Mercat, centre neuràlgic de l'activitat econòmica de la ciutat. Així mateix, es destruïa el traçat islàmic de l'antiga madina musulmana i es forçava al govern municipal a actuar davant la catàstrofe encarregant-se de les obres de reconstrucció. La situació fou tan greu que es desplaçà a València el mateix Joan, aleshores rei de Navarra, per veure la desfeta causada per l'incendi, tal i com també ens explica el nostre notari.

L'enorme quantitat memòries $\mathrm{i}$ textos privats de testimonis contemporanis que ens han arribat certifica l'impacte que causaren el crim i el foc en la societat valenciana del moment. Sembla que l'impacte fou major per a Jaume Vinader, ja què coneixia de primera mà Genís Ferrer, que apareix com a testimoni d'alguns dels documents trobats als seus registres. A més que pel que sabem degué ser testimoni de l'incendi que amenaçà el seu propi domicili situat en la veïna parròquia de Sant Martí.

\subsection{Morts de la reialesa}

Un altre dels blocs temàtics amb especial pes entre les notícies anotades als llibres notarials de Vinader són les morts relacionades amb importants personatges de la reialesa. Concretament, el notari valencià deixa per al record la mort del rei Alfons el Magnànim, en juny de 1458, de la mort de la reina Maria de Castella, muller del Magnànim, en setembre del mateix any, i la mort de Carles, Príncep de Viana, en setembre de 1461. Parlem de tres notícies molt diferents, d'entre les quals destaca clarament la defunció del rei, tant per la llargària -possiblement la notícia més extensa de totes les conservades- com per la informació que ens aporta, no sols de la mort, sinó de les setmanes anteriors al fet. És important recalcar-ho, ja que el nivell de detall que ens aporta és tal que supera fins i tot el relat que ens arriba per Melcior Miralles al Dietari del Capellà. Observem, així doncs, alguns exemples en aquesta direcció. Concretament sobre els rumors que començaren a circular per la ciutat de València sobre el delicat estat de salut del monarca:

\footnotetext{
Diumenge, que era comptat XVI de juliol, de dinar avall, se començà a dir que lo senyor n'Alfonso, per la gràcia de Déu, era mort en Nàpols, de febra, e uns XV dies ans, la senyora reyna, qui era e stava en lo Real del rey, e la ciutat reberen molts correus de la malaltia del dit senyor; hoc hi feren profesó lo dimarts proppasat, per un correu qui portà nova com era milorat al final, que de aquest digmenge fins al divendres, ora de migjorn, la ciutat estava en gran tribulació, que no podien saber si era mort o no. Aquest divendres, era comptat XXI de juliol, e rebut un correu tramés per lo rey de Navarra e per lo mestre de Muntesa, los jurats e altres oficials ho hagueren per cert que lo dit senyor era mort.
} 
Javier Fajardo Paños \& Miquel Faus Faus. La València quatrecentista a través dels ulls d'un notari: les notícies de Jaume Vinader

Gràcies a la consulta de les lletres missives dels jurats de València, conservades a l'Arxiu Municipal de València, hem pogut contrastar i corroborar com aquests rumors dels quals ens parla Vinader són verídics, ja que el 20 de juny de 1458, dies abans de la mort del rei - cal recordar que mor el dia 27 de juny-, els jurats de València adreçaven una carta a Perot Mercader, tresorer del rei a Nàpols, per a transmetre la seua preocupació per l'estat de salut del monarca. ${ }^{8} \mathrm{El} 8 \mathrm{de}$ juliol, ja amb el rei mort, la notícia no havia arribat encara a València, tanmateix, les sospites haurien de estar-hi presents, per això els jurats demanen a Joan de Nàcera, senyor de Xeraco, que acudisca ràpidament a València per «afers concernents al rei». ${ }^{9}$ Unes sospites que el 15 de juliol serien més fortes encara, quan el jurats demanen a Berenguer Mercader, Batlle genera del regne i conseller del rei, i a Pere Pelegrí, jurat de València, que tornen immediatament a la ciutat. ${ }^{10}$

Seria precisament a través dels jurats de Barcelona i, posteriorment, de Joan de Navarra, futur Joan II, com rebrien la confirmació de la mort del rei, els quals, al seu torn, s'haurien informat al port de Barcelona a través de Berto Agosti, mercader napolità. ${ }^{11}$ Com podem observar, les dades coincideixen amb les donades per Vinader en la seua notícia, el que ens porta a sospitar i proposar com a hipòtesis que Vinader, possiblement, es podria haver informat gràcies a contactes que tindria amb membres relacionats amb els jurats de València o el consell de la ciutat, atès que durant les setmanes anteriors a la confirmació de la mort, no hem pogut trobar cap crida pública a València, un dels canals més comuns d'informació per al conjunt d’habitants de la ciutat.

Seguidament, Vinader assenyala amb tot tipus de detall com fos comunicada la notícia a la reina, qui llavors estava a València, al Palau Reial:

\footnotetext{
Fon deliberat que lo governador e mestre racional, e lo batge, e los diputats del general, e los jurats ho denunciassen a la dita senyora reyna. E axí anaren al Real. La senyora reyna està ab gran sospita; lo provencial de preycadors e lo confessor, e los metges, e les viudes ho digueren a la dita senyora de certa manera, bastant que la dita senyora se és mort dos vegades, e retornada vestiren-li un mantell de sanyal e levaren-li tots los paraments de seda, e donaren-li los coxinals de senyal. En aquest temps entraren tots los oficials e denunciaren-ho axí com se pertanya ací. Foren grans plors.
}

El relat no finalitza ací, ja que Vinader prossegueix descrivint com -ara sí- a través de crida pública, el 23 de juliol els jurats comunicaven a la ciutat la mort del rei. El nivell de precisió és tal que Vinader anota fins i tot el nom de qui llegia la crida i la forma de tocar les trompetes:

8 AMV, $\mathrm{LM} \mathrm{g}^{23}$, f. $165 \mathrm{v}$.

9 AMV, $\mathrm{LM} \mathrm{g}^{23}$, f. 172 r.

10 AMV, LM g $\mathrm{g}^{23}$, f. 176r. Llavors, els jurats de València encara no comptaven amb la confirmació de la mort del rei, atès que el 14 de juliol encara continuen adreçant-se al rei Alfons mitjançant lletra missiva

11 AMV, LM g ${ }^{23}$, f. $176 \mathrm{v}$.

SCRIPTA, Revista internacional de literatura i cultura medieval i moderna, núm. 13 / juny 2019 / pp. 1 - 21

ISSN: 2340-4841 · doi:10.7203/SCRIPTA.13.13376 


\begin{abstract}
Lo digmenge aprés, que era comptat XXIII del dit més de juliol del dit any, los jurats de la ciutat havets per nova certa que lo dit senyor era mort. Se vestiren de maregues e feren crida de la dita mort. Los qui feren la crida foren un escrivent, qui legia la crida: Miquel Artús; e dos altres trompetes, sens penós, vestits de maregues. La crida se fahia de part de justícia e jurats de València, sens que no dia honorables. Lo so de les trompetes eren tres bufades: la primera ab sa pausa, la segona ab altra pausa, e la tercera ab sa pausa, sonant cascuna bufada de VIII sons.
\end{abstract}

Vinader, a més a més, fa un relat exhaustiu de la «cerimònia de sepultura», aportant amb gran detall informacions referides a la seua organització i composició: el lloc (la Seu), el dia (28 de juliol), les cases religioses i les confraries de la ciutat que hi eren presents:

[...] les monges de la Çaÿdia, les Menoretes, les Magdalenes de Sent Julià e de Sent Christòfol; amparen totes les confraries, ço és, Sent Narcís, Sent Jordi, Betlem, Ignocens, Sent Christòfol. Sent Jacme ne Sancta Maria no y foren per contesa.

Així com la descripció textual i il lustrativa de la sepultura: «La sepultura fon un alt cadafal ab una alta tomba. Sobre la tomba fon feyt un papalló de fusta de esta forma: [dibuix], tot ardent de ciris e torches». A més a més, descriu extensament la disposició i situació dels principals membres que assistiren a la cerimònia, així com la cerimònia que la mateixa reina celebraria a la setmana següent al convent de la Trinitat.

Considerem que aquesta notícia és d'un gran valor històric ja que ens permet conèixer, d'una banda, la forma en què es transmetien les grans notícies al segle XV, on els rumors i les sospites jugaven un paper molt important. En el cas de la mort d'Alfons el Magnànim observem com hauria de passar gairebé un més perquè els jurats de València conegueren oficialment la notícia, el que explica que setmanes després de la mort del rei encara estigueren enviant-li cartes. D’altra banda, el relat de Vinader ens permet, junt amb la descripció que tenim de Melcior Miralles, fer-nos una idea exacta de com va ser la cerimònia que es celebraria a València en record del rei difunt.

També trobem entre les pàgines notarials els relats de les morts de Maria de Castella i de Carles, príncep de Viana, tot i que de forma molt més breu i concisa.

\title{
2.4. Notícies internacionals
}

L'interès narratiu de Vinader escapa dels successos del seu àmbit geogràfic immediat i de tant en tant trobem alguna notícia referent a altres parts de la Corona d'Aragó o fins i tot de fora d'aquesta. És difícil imaginar en l'actualitat com s'estenia la informació, travessant fronteres, en les societats preindustrials. No obstant això, les noves trobaven els seus canals de difusió i viatjaven conduïdes per mercaders, peregrins i emissaris, com ja hem pogut veure en la notícia de la mort del rei. 
Javier Fajardo Paños \& Miquel Faus Faus. La València quatrecentista a través dels ulls d'un notari: les notícies de Jaume Vinader

En tres ocasions el notari dedica unes línies a comentar les paus entre el rei i els seus enemics. Normalment les notícies arribaven directament del front per missatgers. Un cop estava en la ciutat eren els funcionaris reials i els del municipi els que s'encarregaven de transmetre-la a la població. Generalment, es realitzaven crides públiques en les principals places i punts transitats de la ciutat en un acte codificat en els que diversos ministrers amb trompetes, vestits amb les insígnies reals, acompanyaven un herald que llegia el missatge, on es contava la victòria o el final de les hostilitats. De vegades els actes s'acompanyaven de vols de campanes, alimares i processons. Cal destacar l'enorme importància d'actes com aquest per a la difusió del discurs reial entre el gruix de la població. Les victòries i les derrotes anaven cisellant determinades identitats col lectives en els que el rei, o el responsable de la crida, intentava aconseguir la simpatia de la societat. Un detall subtil en aquest sentit el podem trobar en Vinader qui diu que «se cridà la pau de venecians i florentins ab nosaltres». Aquest plural pot vincular-se amb aquell concepte de «nació dinàstica» segons el qual la població compartiria un sentiment identitari caracteritzat per la vinculació a un mateix rei (Rubio Vela 2012).

Fora de la guerra també arribaven notícies de més enllà del mar. Vinader pren constància en 1456 del gran terratrèmol que el 5 de desembre sacsejà Nàpols danyant un gran nombre d'edificis la ciutat. No obstant això, la més cridanera és la narració que el notari fa de la caiguda de Constantinoble. D’aquesta manera el nostre autor passa a unir-se al conjunt d'autors que es lamentaren de la caiguda de la capital de l'imperi bizantí. El trauma venia causat per la conjunció entre la caiguda de la nova Roma amb la realització de l'inexorable avanç dels turcs que amenaçaven veritablement les fronteres de la cristiandat.

\subsection{Altres}

Finalment, comptem a una sèrie de notícies que per la seua tipologia temàtica no podien ser classificades en cap dels anteriors subgrups. Tanmateix, el seu interés no disminueix. Comptem, com ja s'ha dit en aquest treball, amb el record de les noces de la filla major del notari, Isabel, la qual es casaria el 29 de novembre de 1438 en la parròquia de Sant Martí, on la família Vinader habitava i es socialitzava, amb Jaume Villalonga.

De diferent temàtica és la següent representació textual. Diem «representació textual» perquè no es tracta d'una notícia, en el sentit estricte de recordar un fet concret, sinó més aviat una anotació espontània. Es tracta de la recepta per a elaborar pólvora, a partir de l'anotació dels diferents productes que tots mesclats donen lloc a la matèria explosiva. Aquesta anotació entra dins del grup d'anotacions espontànies que habitualment realitzaven els notaris al principis dels seus llibres. En el cas de Vinader, per exemple, hem pogut observar en altres ocasions l'anotació d'invocacions de caire religiós, les quals podem incloure en aquelles anotacions fetes al marge dels documents notarials.

Finalment, Jaume Vinader demostra amb les seues anotacions estar al corrent dels principals fets polítics que succeïren a la ciutat de València. En aquest sentit, no passa per alt un dels moments 
Javier Fajardo Paños \& Miquel Faus Faus. La València quatrecentista a través dels ulls d'un notari: les notícies de Jaume Vinader

més intensos políticament del Quatre-cents valencià, com és l'enfrontament de la ciutat amb el noble Jaume d'Aragó, qui en la dècada dels seixanta, i dins del marc de la Guerra Civil Catalana, es va alçar contra la Corona en les seues senyories al nord del país. Les hostilitats, però, finalitzarien amb el succés que el notari ens narra, és a dir, la convocatòria d'host per part del govern municipal al capdavant del justícia criminal. En aquest cas, fins i tot, se'ns dóna el nom del justícia de torn, Ramon de Vic, donzell, qui va dirigir l'acció repressiva sota la Senyera. ${ }^{12}$ Finalment, Vinader recorda el desenllaç de l'expedició militar amb l'entrada a la ciutat de Jaume d'Aragó pres pel justícia junt amb la seua família, muller, fills i filles, en el dia de la festivitat de Sant Bartomeu.

\section{Conclusions}

En definitiva, les notícies que hem analitzat en aquest article, possiblement, serien conegudes per Jaume Vinader a través de tres possibles vies: a través dels seus ulls, és a dir, com a testimoni directe; a través dels rumors que corrien per la ciutat, com per exemple el cas que hem vist de la mort del rei, o bé a través de crides públiques que el govern local realitzava, de les quals n’he tenim constància gràcies a la conservació d'algunes d'aquestes en l'Arxiu Municipal de València en la sèrie de Manuals de Consell. A través d'aquestes crides públiques el poder estatal difonia notícies entre el conjunt de la població, generant un sentiment de col lectivitat, de cohesió comunitària, una memòria col lectiva -que podria plasmar-se després en notícies com les de Vinader- i difonent una ideologia especifica. Seria, doncs, aquestes manifestacions públiques, una de les possible vies d'investigació a explotar per la historiografia de cara a copsar en quina mesura, les notícies i les ideologies del poder es filtraven entre la immensa majoria de la societat. El cas de Vinader, almenys, manifesta un indici de filtració considerable entre las classes mitjanes urbanes plasmat a través de les seues notícies escrites sobre esdeveniments polítics de tota mena, des d'entrades reials a la ciutat a grans esdeveniments internacionals, com la caiguda de Constantinoble. Seria interessant, de cara al futur, poder posar en relació tots aquells notaris dels territoris de parla catalana de la Corona d'Aragó amb aquestes pràctiques d'escriptura i poder conformar una base de dades comuna per a poder comparar les tipologies de notícies escrites, i extraure similituds i diferències que ens permeten comprendre un mica millor la lògica memorística dels professionals de l'escriptura als segles baixmedievals i la filtració de les ideologies del poder entre les classes socials mitjanes i baixes.

Finalment, aquesta font ens suggereix que la redacció de notícies de caire memorialista estaria relativament més difosa entre les classes lletrades de la societat baixmedieval, no sols entre els notaris, sinó també entre els no professionals de l'escriptura, com ha demostrat en el seu llibre el professor Enrique Cruselles, on edita alguns llibres de comptes de mercaders i nobles del segle XV valencià, o el professor Francisco Gimeno i Maria Teresa Palasi i la seua edició del llibre de comptes de (Cruselles 2007; Gimeno i Palasí 1986).

12 Sobre la història i evolució de la bandera de la ciutat de València, vegeu el llibre de Pau Viciano (2008).

SCRIPTA, Revista internacional de literatura i cultura medieval i moderna, núm. 13 / juny 2019 / pp. 1 - 21 ISSN: 2340-4841 · doi:10.7203/SCRIPTA.13.13376 
Javier Fajardo Paños \& Miquel Faus Faus. La València quatrecentista a través dels ulls d'un notari: les notícies de Jaume Vinader

\section{Edició de les notícies de Jaume Vinader}

Protocol de 1419, APPV, 9517.

1

Die veneris XXVI madii anni a nativitate Domini Mi CCCC XIX ${ }^{i}$, lo seny major, qui [és] [oro]lotge, apel lat Sent Miquel, pujà al ca[mpa]nar nou.

Protocol de 1427, APPV, 9527.

2

Die martis, prima aprilis, Hugo de Bajés, episcopus Valentini, inmediate post meridiem diem, suum clausit extremum. Requiesquat in pace.

Protocol de 1428, APPV, 9526.

3

Portogall. Die martis, tercia mensis augusti, anno a nativitate Domini millessimo CCCC XXVIII, lo infant de Portogal segons [...] per nom apellat don Pedro [...] d'Alamanya, entrà en València, en la vespra de Sent Jaume de juliol, e reebut molt altament per lo senyor rey n'Alfonso, se n'anà en Portogal aprés moltes festes que lo senyor rey li feu.

Protocol de 1430, APPV, 9525.

4

Die sabbati, XVIIII ${ }^{\circ}$ augusti dicti anni, in hoc civitate Valentina, inceperunt solemniter celebrare festum sancti Ludovici, de cuius corpore gaudet Sedis civitatis eiusdem.

Protocol de 1431, APPV, 9528.

5

Die dominica, XVIIIa februarii, prima dominica in quadragesima, in Sede Valentina, inceperunt, dum sermo divinum evangelisatum de pontificalis et seu mittere barras, in quibus in festivitatibus solemnibus ponuntur pannos de ras in arquis sive archs, que sunt unum ad dexteram, et aliud ad sinistram partes altaris maioris dicte Sedis. In isto presenti anno ad hoc ut homines qui solent circundere dictam Sedem non possint turbare predicantes. 
Javier Fajardo Paños \& Miquel Faus Faus. La València quatrecentista a través dels ulls d'un notari: les notícies de Jaume Vinader

Protocol de 1438, APPV, 9531.

6

Ysabel. Die sabbati, XXVIIII ${ }^{\circ}$ novembris anno a nativitate Domini $\mathrm{M}^{\circ} \mathrm{CCCC}^{\circ}$ XXXVIII ${ }^{\circ}$ Ysabel, filia mia prima, audivit misa altari maiori Sancti Martini civitatis Valentie solemniter, cum Iacobus Vilalonga, sponso suo, et in crastina die consumatum matrimonium. Deo gratias.

Protocol de 1447, APPV, 9538.

In loco de Payporta.

Digmenge, a XXVI del dit mes de febrer del dit any, en la vesprada, entre onze e dotze ores, en Genís Ferrer, fill d'en Joan Ferrer, quondam, notari, qui en l'any proppassat desastradament fou feyt jurat de València, e un sclau seu apel lat Johan, ab Bernat Gaçó de Alboranya (sic), e lo fill d'en Piera e Gualbe, ab cinch altres mataren en lo dit loch de Payporta la dona na Caterina, muller que fon d'en Johan Alfonso, quondam, laurador, e un fill de XXII anys, e un fillet de set anys e una filleta de $\mathrm{V}$ anys, la qual dona e filla xicha lançaren en lo pou de la alqueria de la dita dona, que tenia en lo dit loch. E ultra açò, lexaren en la dita alqueria per morts un moço de la dita dona ab diverses coltellades, e una filla de XIII anys qui s'amagà davall lo lit. Açò fon un feyt molt cruel, fon feyt per enveja e malvolènça, que lo dit en Genís e la muller de aquell, havien a la dita dona de aquest feyt. Tota la ciutat fon molt comoguda. Fon hi provehit molt bé e ab gran diligència per los jurats de València quatorze dies areu tingueren consells, exceptats los digmenges. Die mercurii, a XV de març de matí fon feyt sentencia de la muller del dit en Genís e del sclau e de Bernat Gaçó e de Piera e de Johan del Toro, çò és que la dita dona e lo sclau e Piera e Gaçó foren roçegats e aprés foren degolats en lo Mercat de València, dins un palench que fon feyt, e aprés foren esquarterats lo dit esclau, Piera e Gaçó, e los quarters penxats en dos forques, que feren en lo dit mercat. E en lo tercer dia foren portats tres quarters al dit loch de Payporta, e los altres foren posats per los camins. E la dona estech degolada dins lo dit palench tot aquell dia e tota la nit aprés següent, e lo digous aprés, fins a tres ores pasat mig jorn, e aprés fon soterrada. Lo dit Johan del Toro fon penjat. Açò fon una molt gran sentència que no fon vista tal per los que són vius. Lo dit en Genís fogí de casa sua ans que no fos prés. Fon proceit quan aquell per procés d'absència.

8

Die jovis XVI marcii anno a nativitate Domini $M^{\circ} \mathrm{CCCC}^{\circ} \mathrm{XXXXVII^{ \circ }}$

En lo tercer alberch de la fusteria, a les espatles de Santa Maria de la Mercé, començant a comptar al cantó de la Mercé, se prés foch corrent la novena ora del dit digous a vespre, e fonc tal e tan gran e espaventable, que homens no foren suficients apagar-lo. Cremà ss tota la fusteria, ço és, del cantó de la Mercé fins a l'alberch de Berthomeu Quintana inclusive, lo qual alberch confronta ab lo alberch d'en Miró, lo barber, carrer miger, e traversà lo dit/ foch als alberchs qui estaven al davant, e cremàs tota l'altra part de la fusteria, ço és, qui és a la porta del fosar de Sancta Caterina fins al primer alberch, qui és del especier en la Porta Nova, davant lo obrador apellat d'en Conil. Ultra açò se cremaren tots los alberchs del Trenc e de la Peleria fins a la Pescateria. Encara se cremaren

SCRIPTA, Revista internacional de literatura i cultura medieval i moderna, núm. 13 / juny 2019 / pp. 1 - 21 ISSN: $2340-4841 \cdot$ doi:10.7203/SCRIPTA.13.13376 
Javier Fajardo Paños \& Miquel Faus Faus. La València quatrecentista a través dels ulls d'un notari: les notícies de Jaume Vinader

los alberchs qui ha entre lo carrer dels Manyans fins a la volta qui torna a la Peleria. Encara se cremaren los alberchs qui són en lo carrer principal de la Peleria qui travers Senct Martí fins a la [cora?] lada, on ha un pou. E ultra açò, se cremaren quatre alberchs, dos de cascuna part del carrer de la dita Peleria que va vers la Lotga, a les spatles de la Draperia de lana. Se cremaren moltes cambres per lo foch del Mercat. Fon tan gran foch, del qual tota la ciutat fon tan espantada que no hagueren altre remey sinó cridà: misericòrdia Déu! [Al]tra cosa de gran espavent: la custòdia de Sent Joan, de Sancta Caterina e de Sent Martí, de Sent Salvador, de Sent Berthomeu e de totes les altres parròquies, vingueren ab lo Corpus Christi hoc hi la custòria ${ }^{13}$ ab lo Corpus de Santa Maria de Iesús e de Senct Vicent, e Sent Valero de Ruçafa i, vingueren ab los frares cridant tots altes veus: miserichòrdia!. Durà lo foch de la dita ora fins a les quatre ores aprés miga nit. Plagué a Déu que corregueren tres vents: primer ponent, e aquest vent lançà lo foch en lo T[r]ench; e aprés lebeig, e a la derreria levant, e aquest tornà lo fonch (sic) sobre los alberchs a qui ja eren cremats. E axí, per la clemència de Déu, cessà. Cremàs i molta roba e dos sclaus e tres infants. La gent anà molt torbada e plorant, trahent les robes de lurs cases, buidaren los alberchs./ Los demés e molts que no 'n pogueren traure res. De açò romàs tota la gent tant spantada que dihuyt jorns ne pogueren fer res. E que i no podien menjar, que prou los fes paregué més que fosen a la fi del món, que no en conflicte de enemichs. La ciutat clarejava que i així com lo dia no hac part de la ciutat que fos plena de purnes féu si aquest... ${ }^{14}$

Navarra.

Die jovis $\mathrm{XI}^{a}$ madii anno a nativitate Domini $\mathrm{M}^{\circ} \mathrm{CCCC}^{\circ} \mathrm{XXXXVII}{ }^{\circ}$.

Inter novem e decem oras ante meridiem, Iohannes, Dei gratia rex Navarre, ingressus fuit in hoc civitate, et intrando statim destinavit gresus suos ad fòrum ut videret que destructa erant occasione ignis.

Protocol de 1450, APPV, 9540

Pau.

Die lune, VII ${ }^{a}$ setembris, se cridà la pau de venicians e de florentins amb nosaltres.

Protocol de 1453, APPV, 9519.

Grècia.

Die mercurii XXV ${ }^{a}$ iulii dicti anni, festum sancti Iacobi maioris.

13 Vol dir «custòdia».

14 Resta del foli en blanc. 
Javier Fajardo Paños \& Miquel Faus Faus. La València quatrecentista a través dels ulls d'un notari: les notícies de Jaume Vinader

In ista die fuit publice et per alia manifestatum et divulgatum, quod turqui, hinc est magnus turcus, cum suo exercitu et hostes intrarunt in civitatem Constantinineopulis (sic) et occiderunt imperatorem Gresie [...] fidelissimus christianus et cumeo ducenti quinquaginta grecii sicut quod non remanserunt in hac vita nisi mulieres iuvinas et infantes masculi, a quindecim nimis citra et in hac die villa famosa de Empera subdicta et populata, Iaunentium obidentiam et dominium tradidit eidem turquo. Ista novitas fuit prava sicut quod a morte Christi citra non fuit audita maior nec similis. Hoc fuit in XXVIII madii istius anni. In ista die perit monarca mundi et tota eius monarchia iste enim dedit $\mathrm{Si}(\mathrm{l})$ vestro Romam dotavit Eclesiam fundavit imperium Alamanie ab septem realmis et regibus.

Protocol de 1454, APPV, 9519.

Albayda.

Die iovis VIIII mensis angisti dicti anni, lo honorable mossén Berenguer Mercader, cavaller, batle general, de consell de micer Gabriel de Palomar, de micer Johan de Sala, el menor, de micer Jacme Garcia e de micer Macià Cardona, donà sentència sobre lo criminal d'Albayda, declarant lo senyor rey poder quitar e cobrar lo criminal per XXXVI sous. Reebé la sentència en Jacme d'Anglesola, notari.

Protocol de 1455, APPV, 9526.

Papa.

Die lune XXIIII marcii obivit dominus noster papa Nicolaus.

Pau.

Die iovis XXVII marcii anno nativitate Domini M CCCC L ${ }^{i}$ quinto

En aquest dia, fon publicada en València la pau del senyor rey ab venecians, ab lombarts e ab florentins e ceneses, e ab tota Ytalia, exceptat ab genoveses. E crides se feren ab ministres e trompetes ytalianes e les trompetes de la ciutat e ab sobrevestes reals.

Festum e Pasce.

Die dominica $\mathrm{VI}^{\mathrm{a}}$ mensis aprilis anno a nativitate nomini $\mathrm{M}^{\circ} \mathrm{CCCC}^{\circ} \mathrm{L}^{\mathrm{o}}$ quinto. Resurreccionis Domini.

Die martis, VIII a aprilis fuit electus in papa dominus nostri Alfonsus de Borja, episcopus et cardinalis civitatis Valentie. Fuit post eleccionem, nominatus Calistrius tercius. 
Javier Fajardo Paños \& Miquel Faus Faus. La València quatrecentista a través dels ulls d'un notari: les notícies de Jaume Vinader

Papa.

Die sabbati XXVI $I^{a}$ aprilis anno a nativitate Domini $M^{\circ} C C C C^{\circ} L^{\circ}$ quinto.

En esta jornada vingué nova certa com Nicholau, papa quint, era mort. Fon deliberat per lo capitol de la Seu de València que li fos feta sepultura solempne e axí fon feyt. E axi ss segui que lo diluns de matí, que era comptat XXVIII, li fon feta solempne sepultura o remembrança. E seguis que així com foren fora de la sepultura e les gens se...em vench correu a l'honorable mossèn Bernat Sanç, prevere, procurador del senyor cardenal e bisbe de València, Com lo dit senyor cardenal era estat elet en papa. Fon una tan gran alegria en la present ciutat que los vivents no havien vista tal cosa. Súbitament fon sonar lo seny Miquel e aprés totes les campanes del campanar, responent les parròquies e los monestirs. La gent se comens e venien com a pluja a saber que era de tanta festa. $\mathrm{E}$ no obstant, plogués bé e rallacen les canals, la gent venia a la Seu tots estaven quasi torbats de sobre de al legria. Lo clero se ajustà e vistent-se les capes d'or, plocesso solemne se fa entorn de la Seu, cantant Te Deum laudamus, les germanes del papa ab les nebodes hi foren grantment acomplaydes per lo compte de Cocentayna, per nobles, barons, cavallers, ciutadans, frares, dones, e altres gents. La festa durà tres dies. En les nits, les alimares se feren per la església.

Protocol de 1456, APPV, 9521.

Nàpols.

Die dominica $\mathrm{V}^{\mathrm{a}}$ decembris dicti anni.

In hac die, pulsata quarta ora post mediam nocte quinta ora fuit terramotus in Civitate Napolis.

Protocol de 1458, APPV, 9542.

De Trenitate.

Die veneris, $\mathrm{VI}^{\mathrm{a}}$ ianuarii anni nativitate Domini $\mathrm{M}^{\mathrm{i}} \mathrm{CCCC}^{\mathrm{i}} \mathrm{LVIII}{ }^{\mathrm{i}}$, quod dies celebrabatur festum Aparicionis Domini, fuit celebratur in ecclesia nova sancte Trinitatis missa alta in altari maiori dicte ecclesie et monjales inceperunt facere oficium in coro novo.

De la indulgència atorgada a la Seu de València.

Die lune, XVII aprilis anno a nativitate Domini $\mathrm{M}^{\circ} \mathrm{CCCC}^{\circ} \mathrm{LVIII}^{\circ}$, honorabilis reberendusque dominus Anthonius Bou, canonicus Sedis Valencie, qui in mense februarii anni nativitati Domini $\mathrm{M}^{\mathrm{i}} \mathrm{CCCC}^{\mathrm{i}} \mathrm{LVII}^{\mathrm{i}}$ missus fuerat per honorabilem capitulum Sedis Valencie sanctissimo domino nostro pape Calistro, in embaxatorem ex quo dictus dominus noster papa, qui episcopus Sedis Valencie fuit, deinde papa. Et quia idem dominus noster papa acceptavit illum cum magna onore et reverencia, concessit eidem Sedi indulgenciam plenariam, ut notum est, et multas reliquias intravit in civitate Valencie. Hoc modo quod omnes canonici exierum usque ad crucem loci de Quaraxet, et 
Javier Fajardo Paños \& Miquel Faus Faus. La València quatrecentista a través dels ulls d'un notari: les notícies de Jaume Vinader

iurati et gubernator et omnes alii nobiles et milites exierunt ad sanctum Anthonium et ultra usque ad quedam pontium, quod est intra dicte trasasto (?) sancto Anthonio. Et ita intrarunt ad palacium regali, ubi era domina regina, et deinde ad palacium episcopalem.

Indulgència.

Die lune XIIII augusti anni nativitate Domini Mi CCCC LVIII.

En aquest dia, que fon vespra de Sancta Maria d'agost, commençà la Seu de València a dar indulgència de pena e culpa per lo sanct pare papa Caliste tercer atorgada a la Seu de València.

Die martis, XV augusti festum beate Marie.

De magnifico principe et domino dominus Alfonso, rege Aragonum.

Diumenge, que era comptat XVI de juliol, de dinar avall, se començà a dir que lo senyor n'Alfonso, per la gràcia de Déu, era mort en Nàpols, de febra, e uns XV dies ans, la senyora reyna, qui era e stava en lo Real del rey, e la ciutat reberen molts correus de la malaltia del dit senyor; hoc hi feren profesó lo dimarts proppasat, per un correu qui portà nova com era milorat al final, que de aquest digmenge fins al divendres, ora de migjorn, la ciutat estava en gran tribulació, que no podien saber si era mort o no. Aquest divendres, era comptat XXI de juliol, e rebut un correu tramés per lo rey de Navarra e per lo mestre de Muntesa, los jurats e altres oficials ho hagueren per cert que lo dit senyor era mort. Convocaren consell e deliberaren de la sepultura del dit senyor. Fon deliberat que lo governador e mestre racional, e lo batge (sic), e los diputats del general, e los jurats ho denunciassen a la dita senyora reyna. E axí anaren al Real, la senyora reyna està ab gran sospita; lo provencial de preycadors e lo confessor, e los metges, e les viudes ho digueren a la dita senyora de certa manera, bastant que la dita senyora se és mort dos vegades, e retornada vestiren-li un mantell de sanyal e levaren-li tots los paraments de seda, e donaren-li los coxinals de senyal. En aquest temps entraren tots los oficials e denunciaren-ho axí com se pertanya ací. Foren grans plors. A la conclusió, la dita senyora però se comanà a la dita ciutat e als amichs de son marit. Foren-li fets grans profertes d'ací avant tota la ciutat, ço és, oficials e cavallers anaren vestits de maregues. Lo dissabte a XXII de juliol, tots los oficials se vestiren de maregues.

Lo digmenge aprés, que era comptat XXIII del dit més de juliol del dit any, los jurats de la ciutat havets per nova certa que lo dit senyor era mort. Se vestiren de maregues e feren crida de la dita mort. Los qui feren la crida foren un escrivent, qui legia la crida: Miquel Artús, e dos altres trompetes, sens penos vestits de maregues. La crida se fahia de part de justícia e jurats de València, sens que no dia honorables. Lo so de les trompetes eren tres bufades: la primera ab sa pausa, la segona ab altra pausa, e la tercera ab sa pausa, sonant cascuna bufada de VIII sons. Manaven que no fos que algun fes o paràs obrador de son art ne obrisen portes fins fos feta la sepultura. Faien sonar la Seu e totes les parròquies tres tochs de matí e tres aprés dinar. Lo divendres aprés següent, que era comptat XXVIII de Juliol, se feu la sepultura en la Seu molt altament. Los dits jurats amparen dotze entre nobles e cavalers e ciutadans, convidaren tots los homens e dones e viudes de bé que fossen en la sepultura; annaren les monges de la Çaydia, les Menoretes, les Magdalenes de Sent Julià 
Javier Fajardo Paños \& Miquel Faus Faus. La València quatrecentista a través dels ulls d'un notari: les notícies de Jaume Vinader

e de Sent Christòfol; amparen totes les confraries, ço és, Sent Narcís, Sent Jordi, Betlem, Ignocens, Sent Christòfol. Sent Jacme ne Sancta Maria no y foren per contesa. La sepultura fon un alt cadafal ab una alta tomba, sobre la tomba fon feyt un papalló de fusta de esta forma: (dibuix), tot ardent de ciris e torches.

Foren tots los barons, nobles, cavallers, ciutadans e los oficials ab esta diferència, que los oficials de València staven $\mathrm{ab}$ maregues comunes e los oficials reals així com son governador, mestre racional e batle vestits de sanyals tots bé, e mols. Foren plus de XXX de casa de la senyora reyna ab capirons vestits, les dones de casa de la dita senyora. La badesa de la Çaydia a(b) totes ses monges estaven entre la cort e lo lit, a la part del pistoler; e la prioresa de magdalenes ab ses monges staven davall lo evangelister; X monges menoretes e legues staven davant lo cor, al peu del lit; les monges de sent Julià staven davant lo lit e lo altar. Les confraries staven entorn de la Seu. La gent era tanta que no era persona que pogués pasejar per la Seu. Foren los capellans e totes les creus de València.

La senyora reyna feu semblant sepultura en la Trenitat lo dimecres aprés següent en esta forma: que les portes foren tancades. Solament hi entraren les dones de bé, soles sens ${ }^{15}$ dones vestides de doll ab màrega, tots los monestirs, uns aprés d'altres, vingue(re)n a la Trenitat e sobre la tomba absolien, e aprés se n'anaven. Les monges de la Çaydia hi foren, les Monges Magdalenes hi foren, les de Sant Julià e VIII menoretes, les magdalenes feren una solemne absolució ab acordes. La senyora reyna amprà tots los hòmens de bé e vingeren del Real a la Trenitat ab molt bel ordre, e fon aquest: los saigs del justícia criminal primer, aprés los vergés dels jurats, del batle e de la diputació, e los porters del governador, de tres en tres ab maregues, aprés lo governador e un jurat e un diputat, aprés mestre racional, un jurat ciutadà e un diputat, aprés lo batle e un jurat e un diputat; e d'aquí avant venien los vescomptes, barons, nobles, cavallers, ofecials e ciutadans fins als scuders. Aprés vingueren los de la casa de la senyora reyna, ço és, don Hugo de Cardona ab lo general de Preycadors, lo confessor amb don Luis Maça, e axí fins al derrer. Eren tant gent, que los que ls vehien venir dehien que may havien vista tant bella cosa, e tots se n'entraren en la Trenitat. Aprés vingué la Seu e totes les parròquies ab les creus e ab lo bisbe e feren ofici molt solemne.

De morte egregie regine Aragonum

Die lune IIII ${ }^{a}$ setembris, Maria, regina Aragonum quod uxor fuit domini regis Alfonsi, constituta fuit in articulo mortis in nocte huius modi, inter XI ora et XII obuit, in media nocte. Ad notificantum mortem suam, simboli et campane in statu medie nocti pulsati fuerunt.

Die iovis VII a septembris, dicti anni, fon soterrada de matí, en la Trinitat. Fon-li feta tal honor com fon feta al senyor rei, hoc adito, quod totes les dones de bé e les donzelles e les altres dones e sclaves de casa, anaren derre (sic) lo cors, ço és, darrere los homens, plorant molt agrament.

Die sabati VIIII ${ }^{\circ}$ septembris dicti anni, vench nova com havien elet en papa lo cardenal de Cena e fon nomenat Pius secundus.

15 Frase incompleta

SCRIPTA, Revista internacional de literatura i cultura medieval i moderna, núm. 13 / juny 2019 / pp. 1 - 21 ISSN: 2340-4841 · doi:10.7203/SCRIPTA.13.13376 
Javier Fajardo Paños \& Miquel Faus Faus. La València quatrecentista a través dels ulls d'un notari: les notícies de Jaume Vinader

Protocol de 1460, APPV, 9038.

La Seu

Die jovis $X^{a}$ ianuarii anno a nativitate Domini $M^{\circ} C C C C^{\circ} L X^{o}$, començaren a cavar los fonaments de la Seu, per rahó de la arcada que hi han afegit.

Protocol de 1461, APPV, 9039.

De morte Caroli primogeniti Aragonum.

Die sabbati, pulsata quinta ora post meridiem, intitulato XXXI setembris, anni nativitate Domini M CCCC LX primi, vench nova que dimarts proppassat, que era comptat XXII del present mes, Don Carles, primogènit de Don Johan, rei d'Aragó, per la gràcia de Déu, era mort de pasió còlica.

Protocol de 1464, APPV, 9545.

Recepta per fer pòlvora

Tres quarts de sofre

Tres onzes de carbó

Una liura de salpestre

De pace Castelle

Dimarts a XV de maig del dit any, corrent la novena ora, vench correu ab letra del senyor rey, com havia fermada pau ab lo rei de Castella. De continent, per bona nova, sonaren totes les campanes. E en lo matí, qui era comptat XVI del dit mes, fon feta crida real ab cinch trompetes a la ytaliana, e quatre ministrers e un erau e tres trompetes de la ciutat e una cornamussa e caballs ab sobrevestes reals, e lo vespres feren alimares, e digous de matí, misa solemne en la Seu e processó a la Verge de Gràcia. Foren-hi los monestirs e monges de Sent Vicent, e comptes, vescomptes, oficials e barons, etc.

Don Jacme d'Aragó

Die mercurii prima mensis augusti dicti anni, quatre ores aprés migjorn, lo honorable En Ramon de Vich, donzell, iusticia de la ciutat de València, prés la Senyera de la dita ciutat del portal dels Serrans e anà ab l'ost de València al loch de Maçamagrell contra don Jacme d'Aragó.

Die veneris, festum sancti Bartolomei XVIII ${ }^{a}$ dictorum mensis et anii, entrà gloriosament lo justícia ab la barenda (sic) e ab Don Jacme e sa muller, dos fills e dos filles presos, ab tota la ost.

Protocol de 1465, APPV, 9546.

SCRIPTA, Revista internacional de literatura i cultura medieval $i$ moderna, núm. 13 / juny 2019 / pp. 1 - 21 
Javier Fajardo Paños \& Miquel Faus Faus. La València quatrecentista a través dels ulls d'un notari: les notícies de Jaume Vinader

MIQUAEL NOMEN EIUS DICTI SIMBOLI

Die martis, prima mensis octobris anni nativitate Domini $\mathrm{M}^{\mathrm{i}} \mathrm{CCCC}^{\mathrm{i}} \mathrm{LXV}^{\mathrm{i}}$, currente sexta ora post meridiem, relogium vocatum (Michael), decurente sua massa, ex duabus fornaceris factum et formatum fuit in platea Sedis et Curiarum, presentibus crucibus parrochialis et ligno sancte Crucis et episcopo et toto clero valentino, et cum dicta massa superaret, ipso facto derunt Deo laures et gratias.

Die dominica, XXVII octobris dicti anni, cimbulum nuncupatum relogium, fuit solemniter benedictum cum professione solemni, in qua fuerunt omnes ordines et omnes parrochias et episcopus, et fuerunt patritini egregii viri Petrus de Urrea, gubernator; Raymundus de Vich, domicellus, juratus huius anni in capite; et Franciscus Gilaber, comes de Oliva. Padrina honorable (en blanc), filia honorabili Guillermi Çaera, rationalis.

Die mercurii, intitulato quinta mensis decembris dicti anni millesimi quadringentisimi sexagesimi quinti, in qua diem celebrabatur festum sancte Barbere, dictum relotgium fuit assuntum in campanario, curentes secunda ora post meridiem, et hec dicta suficiant.

Protocol 1466, APPV, 9547.

30

A XVIII de juliol del present any començaren a menjar del forment d'aquest any.

Protocol 1467, APPV, 9549.

31

Die jovis, decima octava mensis junii, anno a nativitate domini $\mathrm{M}^{\circ} \mathrm{CCCC}^{\circ} \mathrm{LXVII}^{\circ}$, pulsada tercia ora post meridiem, dominus rex Johannes veniens Terracone in custodiatorium galearum justus fuit in Gradu maris Valentie, et ibi receptus per juratos, comites, vicecomites et barones. Ingressus fuit Valentie et fecit orationem in Sede, et deinde fuit ad Santam Mariam Gratie, et regresus in Regali suo. 
Javier Fajardo Paños \& Miquel Faus Faus. La València quatrecentista a través dels ulls d'un notari: les notícies de Jaume Vinader

\section{Bibliografia}

Andrés Robles, F. (et ali) (1990) Inventario de fondos notariales del Real Colegio Seminario de Corpus Christi de Valencia, València.

Almarche, F. (1919) Historiografia valenciana: Catálago bibliográfico de dietarios, libros de memorias, diarios, relaciones... inèdites y referentes a la bistoria del antiguo Reino de Valencia, València.

Benito Goerlich, D. (1998) ElRealMonasterio de la Santísima Trinidad, València, Consell Valencià de Cultura.

Cruselles, E. (2007) Los comerciantes valencianes del siglo XV y sus libros de cuentas, Castelló de la Plana, Universitat Jaume I.

Cruselles, J. M. (1998) Els notaris de la ciutat de València: activitat professional i comportament social a la primera meitat del segle XV, Barcelona, Fundació Noguera.

Escartí, V. J. (1995) «Edició de les notícies de Gaspar Eiximeno (1489-1492), Saitabi: revista de la Facultat de Geografia i Història, 45, pp. 157-168.

—. (1998) Memòria privada: literatura memorialística valenciana del segle XV al XVIII, València, Eliseu Climent.

Gimeno Blay, F., Palasí Fas, M. T. (1986) «Del negocio y del amor: el dietario del mercader Pere Seriol (1371), Saitabi: revista de la Facultat de Geografia i Història, 36, pp. 37-56.

Gómez de Valenzuela, M (2015) Al margen de los protocolos notariales aragoneses, memorias y crónicas, antologia de poesia notarial y notes varias (1429-1711), Saragossa, El Justicia de Aragón.

Mas, A. (2013) «La Germania de Mallorca narrada per un contemporani: la descripció de la Germania del notari Joan Morro», Bolletí de la Societat Arqueològica Lul liana: Revista d'estudis històrics, 69, pp. 311-322.

Pertegás, R. (1930) «Efemérides notariales», Anales del Centro de Cultura Valenciana, 3, pp. 191-201.

- (1931) «Efemérides notariales», Anales del Centro de Cultura Valenciana, 4, pp. 1-20.

Pons Alós, V. (2010-2011) «La pràctica notarial valenciana medieval. Los libros de los notarios», Saitabi: revista de la Facultat de Geografia i Història, 60-61, pp. 41-62.

Rodrigo Lizondo, M (ed.) (2011) Melcior Miralles: Crònica i dietari del capellà d'Alfons el Magnànim, València, Publicacions Universitat de València.

Rosselló, R. (1990) L'assalt de Ciutadella (1558) descrit pel notari Joan Morro, Felanitx, Gráficas Llopis.

Rubio Vela, R. (1995) L'escrivania municipal de València als segles XIV-XV: burocràcia, política i cultura, València, Consell Valencià de Cultura.

- (2012) El patriciat i la nació: sobre el particularisme dels valencians en els segles XIV i XV, CastellóBarcelona, Fundació Germà Colon Domènech-Publicacions de l'Abadia de Montserrat.

Sans i Travé, J. M (ed.) (1992) Dietari o llibre de jornades (1411-1484) de Jaume Safont, Barcelona, Fundació Noguera.

Viciano, P. (2008) Barres i corones. La bandera de la ciutat de València (segles XIV-XIX), Catarroja, Afers.

SCRIPTA, Revista internacional de literatura i cultura medieval i moderna, núm. 13 / juny 2019 / pp. 1 - 21 